\title{
MicroRNA-155 regulates the proliferation, cell cycle, apoptosis and migration of colon cancer cells and targets CBL
}

\author{
HUA YU $^{1 *}$, WEILING XU ${ }^{2,3^{*}}$, FANGCHAO GONG $^{4}$, BAORONG CHI $^{3}$, JUNYI CHEN ${ }^{1}$ and LING ZHOU ${ }^{1}$ \\ ${ }^{1}$ Department of General Surgery, The Branch of Shanghai First People's Hospital, Shanghai 200081; \\ Departments of ${ }^{2}$ Radiology, ${ }^{3}$ Gastroenterology and ${ }^{4}$ Thoracic Surgery, The First \\ Hospital of Jilin University, Changchun, Jilin 130021, P.R. China
}

Received August 3, 2016; Accepted June 8, 2017

DOI: $10.3892 / \mathrm{etm} .2017 .5085$

\begin{abstract}
MicroRNA-155 (miR-155) is a well-studied miR and acts as an oncomiR in numerous cancer types. However, the biological functions of miR-155 in colon cancer as well as its target genes have remained to be fully elucidated. In order to investigate the biological functions of miR-155, MTT, colony formation and wound healing assays, cell cycle analysis and detection of apoptosis were performed. The results demonstrated that miR-155 promoted the proliferation of colon cancer cells and enhanced their colony formation capacity, promoted their cell cycle progression and inhibited apoptosis. miR-155 also promoted the migration of colon cancer cells. In the present study, casitas B-lineage lymphoma was identified as a novel target of miR-155. The present study suggested that miR-155 functions as an oncomiR in colon cancer cells and may become a promising therapeutic target for colon cancer therapy.
\end{abstract}

\section{Introduction}

MicroRNAs (miRs) are endogenous small non-coding RNAs and exert their functions by binding to the 3 '-untranslated region (3'UTR) of the messenger RNAs of target genes, resulting in inhibition of translation or mRNA degradation (1-4). miRs are involved in numerous cellular processes, such as proliferation, migration, cell cycle, cell apoptosis and energy metabolism. Aberrant expression of miRs has been detected in numerous tumor types and the dysregulation of miRs is likely to be associated with the development of tumors (5).

Correspondence to: Dr Junyi Chen or Dr Ling Zhou, Department of General Surgery, The Branch of Shanghai First People's Hospital, 1878 North Sichuan Road, Shanghai 200081, P.R. China

E-mail: junyi_Chen22@163.com

E-mail: ling_zhou06@sina.com

${ }^{*}$ Contributed equally

Key words: microRNA-155, casitas B-lineage lymphoma, proliferation, cell cycle, apoptosis, migration, colon cancer
The host gene of miR-155 is B cell integration cluster, which is located in chromosome 21q21. miR-155 is a well-known miR that is associated with the inflammatory system. miR-155 is closely linked with proliferation, apoptosis and differentiation of lymphocytes (6-8), and regulates the balance of type 17 T-helper/T-regulatory cells, the imbalance of which is a major cause of numerous auto-immune diseases (9). miR-155 has been demonstrated to be overexpressed in various types of tumor tissue, such as renal carcinoma and hepatocellular carcinoma, compared with that in the adjacent normal tissues, and is associated with the malignant clinicopathological characteristics of tumors $(10,11)$. Furthermore, miR-155 has been reported to be associated with the proliferation, invasion, apoptosis and cell cycle of tumor cells in vivo and in vitro $(10,11)$.

Casitas B-lineage lymphoma (CBL) is an E3 ubiquitin ligase, which mediates the ubiquitinated degradation of activated receptor tyrosine kinases (RTKs), resulting in a halt in RTK-mediated signaling. CBL is associated with the proliferation, apoptosis, invasion and migration and is linked to the development of tumors (12-15). CBL also regulates the proliferation, differentiation and survival of human mesenchymal-derived osteoblasts (16). It has also been reported that CBL acts as a tumor suppressor in colon cancer cells $(17,18)$.

miR-155 has been previously demonstrated to be overexpressed in colon cancer tissues compared with that in adjacent tissues $(19,20)$. However, the biological functions and downstream targets of miR-155 in colon cancer have remained elusive. In the present study, the effects of miR-155 on colon cancer cells were explored. The results demonstrated that miR-155 regulated the proliferation, cell cycle, apoptosis and migration of colon cancer cells through targeting CBL. The present study indicated that miR-155 may become a promising therapeutic target for the treatment of colon cancer.

\section{Materials and methods}

Cell culture. The HCT-116 colon cancer cell line was obtained from the American Type Culture Collection (Manassas, VA, USA) and cultured in RPMI-1640 medium (Gibco; Thermo Fisher Scientific, Inc., Waltham, MA, USA) with $10 \%$ fetal bovine serum (FBS; Gibco; Thermo Fisher Scientific, Inc.) in a humidified atmosphere at $37^{\circ} \mathrm{C}$ with $5 \% \mathrm{CO}_{2}$. 
Transfection. miR-155 mimics (5'-UUAAUGCUAAUCGUG AUAGGGGU-3') and inhibitor (5'-AAUUACGAUUAGCAC UAUCCCCA-3') or their corresponding negative controls were purchased from Biomics Biotech (Nantong, China). Cells were harvested and seeded in 6-well plates at a density of $1 \times 10^{5}$ cells/well. After $24 \mathrm{~h}$ of incubation, the cell medium was changed to serum-free medium. After additional culture for $6 \mathrm{~h}, 4 \mu \mathrm{g}$ DNA or 100 pmol RNA were transfected into cells using Lipofectamine 2000 reagent (Invitrogen; Thermo Fisher Scientific, Inc.) according to the manufacturer's protocol.

Reverse-transcription quantitative polymerase chain reaction $(R T-q P C R)$. At $48 \mathrm{~h}$ after transfection, cells in each group were collected. Total RNA was extracted using TRIzol reagent (Invitrogen; Thermo Fisher Scientific, Inc.) according to the manufacturer's protocol. The RNA was reverse-transcribed and the levels of miR-155 were detected by RT-qPCR (SYBR Green method) with a miR-155 detection kit (Biomics Biotech; catalog number, BK3100) according to the manufacturer's instructions. The miR-155 levels were normalized to U6 small hairpin RNA and the relative miR-155 levels were calculated using the $2^{-\Delta \Delta C q}$ method (21). Total RNA was reverse-transcribed into complementary (c)DNA using Moloney murine leukemia virus reverse transcriptase (Promega Corp., Madison, WI, USA) and random primer. The mRNA levels of CBL were detected by RT-qPCR with cDNA as templates and primers as follows: CBL forward, 5'-GGACCAGTGAGTTGGGAG TTATTACT-3' and reverse, CBL, 5'-GGCAAGACTTCACTG TGAAGTCA-3'; GAPDH forward, 5'-AAGGTCGGAGTC ACCGGATT-3' and reverse, 5'-CTGGAAGATGGTGATGGG ATT-3'. The PCR mixture contained the following: $2 \mu 1 \mathrm{cDNA}$, $1 \mu 1$ forward primer, $1 \mu 1$ reverse primer, $10 \mu 12 \mathrm{X}$ SYBR mix, and $\mathrm{ddH}_{2} \mathrm{O}$ up to $20 \mu \mathrm{l}$. The thermocycling conditions were the following: $95^{\circ} \mathrm{C}$ for $10 \mathrm{~min} ; 95^{\circ} \mathrm{C}$ for $10 \mathrm{sec}, 62^{\circ} \mathrm{C}$ for $20 \mathrm{sec}$, $72^{\circ} \mathrm{C}$ for $30 \mathrm{sec}$ for 40 cycles; then $4^{\circ} \mathrm{C}$ for $5 \mathrm{~min}$. The mRNA levels of CBL were normalized to GAPDH and relative mRNA levels of CBL were calculated using the $2^{-\Delta \Delta \mathrm{Cq}}$ method (21).

MTT assay. Cells were seeded in 96-well plates with 6,000 cells in each well. The cells were then transfected with miR-155 mimics, negative control of mimics, miR-155 inhibitor or negative control of inhibitor. At $0,24,48,72$ and $96 \mathrm{~h}$ after transfection, $5 \mathrm{mg} / \mathrm{ml}$ MTT was added to each well. After incubation for an additional $4 \mathrm{~h}$, the supernatant was removed and $200 \mu 1$ dimethyl sulfoxide was added to each well. The absorbance was measured using a microplate reader at $490 \mathrm{~nm}$.

Colony formation assay. After transfection with miR-155 mimics, miR-155 inhibitor or their negative controls, 200 cells were incubated in 6-well plates and cultured in an incubator containing $5 \% \mathrm{CO}_{2}$ at $37^{\circ} \mathrm{C}$. At 7 days post-incubation, the cells were stained with crystal violet for $30 \mathrm{~min}$ and the number of colonies was counted after washing with PBS.

Cell cycle analysis. Cells were harvested after transfection with miR-155 mimics, miR-155 inhibitor or their corresponding negative controls and fixed in ice-cold 70\% ethanol at $4^{\circ} \mathrm{C}$ overnight. Cells were washed with PBS and stained with a cell cycle detection kit (Beyotime Institute of Biotechnology, Haimen, China) in the dark for $30 \mathrm{~min}$. The cell cycle distribution was then analyzed with a FACScalibur flow cytometer (BD Biosciences, Franklin Lakes, NJ, USA).

Apoptosis assay. Cell apoptosis was detected with an Annexin V-fluorescein isothiocyanate (FITC)/propidium iodide (PI) Apoptosis Detection kit (KeyGEN Biotech, Jiangsu, China) according to the manufacturer's protocol. After transfection with miR-155 mimics, miR-155 inhibitor or their corresponding negative controls, the cells were washed with PBS and re-suspended in $500 \mu \mathrm{l}$ binding buffer. After addition of $5 \mu \mathrm{l}$ Annexin V-FITC and $5 \mu \mathrm{l}$ PI, the cell suspension was incubated for $15 \mathrm{~min}$ in the dark. Cells were then analyzed with a FACScalibur flow cytometer.

Wound healing assay. Cells were seeded in a 6-well plate and transfected with miR-155 mimics, miR-155 inhibitor or their negative controls. When cells had grown $90 \%$ confluent, scratches were made to the monolayer surfaces of cells with sterile micropipette $200 \mu 1$ tips (Beyotime Institute of Biotechnology). After washing with serum-free medium for several times to remove cell debris, cells were cultured in serum-free medium to eliminate the influence of cell proliferation and images of scratches were captured at 0 and $24 \mathrm{~h}$. The relative migration rate was calculated as follows: Relative migration rate $=($ gap between the edges at $0 \mathrm{~h}$-gap between the edges at $24 \mathrm{~h}$ )/gap between the edges at $0 \mathrm{~h}$.

Western blot analysis. At $48 \mathrm{~h}$ after transfection, cells in each group were collected. Total protein was extracted from cells using radioimmunoprecipitation assay lysis buffer (Beyotime Institute of Biotechnology). Protein concentrations were determined with an enhanced bicinchoninic acid protein assay kit (Beyotime Institute of Biotechnology). A total of $40 \mu 1$ of protein was loaded and subjected to $10 \%$ SDS-PAGE. The separated protein was then transferred onto polyvinylidene fluoride (PVDF) membranes (Millipore, Bedford, MA, USA). After blocking with $5 \%$ skimmed milk at $37^{\circ} \mathrm{C}$ for $1 \mathrm{~h}$, the PVDF membranes were incubated with primary antibodies against CBL (1:1,000 dilution; Santa Cruz Biotechnology, Inc., Dallas, TX, USA; catalog number, sc-170) and $\beta$-actin $(1: 2,000$ dilution; Santa Cruz Biotechnology, Inc.; catalog number, 4970) at $4^{\circ} \mathrm{C}$ overnight. After washing with Tris-buffered saline containing Tween-20, the membranes were incubated with horseradish peroxidase-labeled secondary antibodies (1:5,000 dilution; Beyotime Institute of Biotechnology; catalog number: A0208) at room temperature for $60 \mathrm{~min}$. The target bands were visualized using an enhanced chemiluminescence detection kit (Beyotime Institute of Biotechnology) according to the manufacturer's instructions. Relative protein levels of CBL were calculated using $\beta$-actin as an internal reference.

Luciferase reporter assay. A luciferase reporter assay was employed to detect whether miR-155 bound to the 3'UTR of CBL directly. As predicted by TargetScan (http://www .targetscan.org/), fragments of CBL mRNA containing wild type (WT) or mutant (MUT) miR-155 binding sites or lacking the miR-155 binding site (DEL) were respectively cloned into the pMIR-REPORT luciferase reporter vector (Ambion, San Diego, CA, USA). HCT-116 cells were seeded into 24-well plates and $0.2 \mu \mathrm{g}$ luciferase reporter plasmid WT, MUT or 

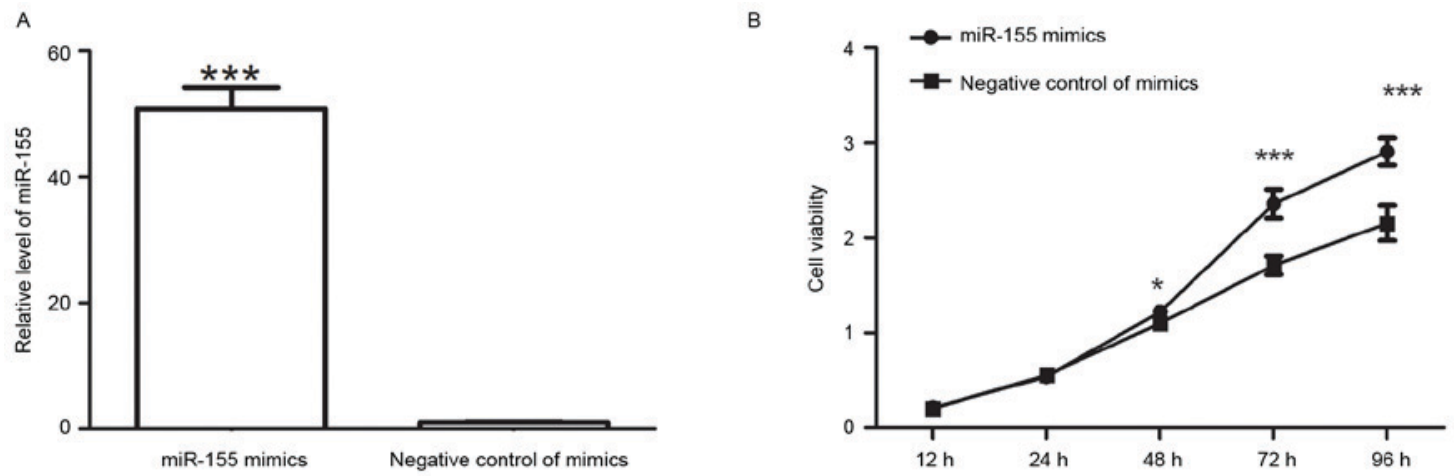

D
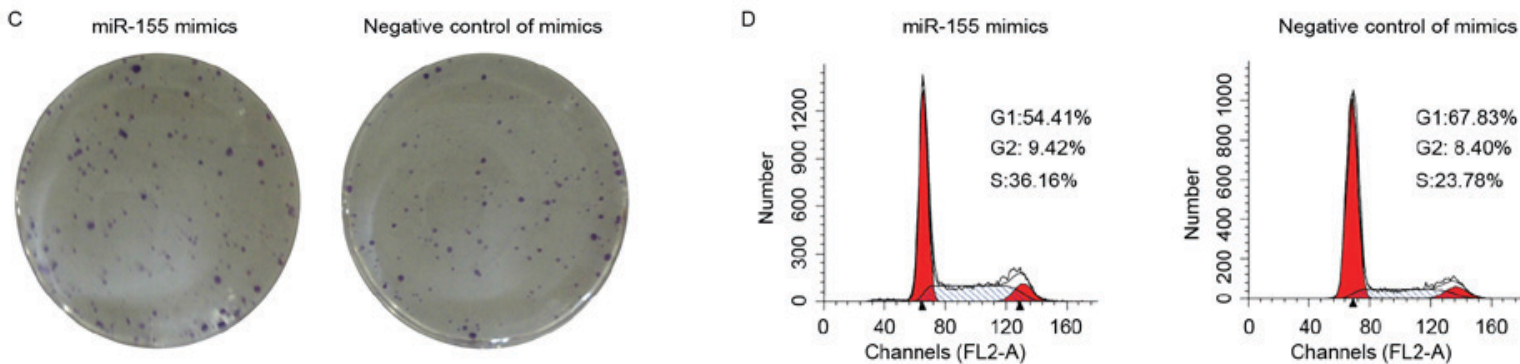

Figure 1. Upregulation of miR-155 promotes the proliferation and cell cycle of colon cancer cells. (A) After transfection with miR-155 mimics, the levels of miR-155 were detected by reverse-transcription quantitative polymerase chain reaction. The mRNA levels were normalized to U6 small hairpin RNA. (B) The viability of colon cancer cells after transfection with miR-155 mimics was detected by an MTT assay. (C) A colony formation assay was performed after transfection with miR-155 mimics. (D) After transfection with miR-155 mimics, the cell cycle was analysed by flow cytometry. Values are expressed as the mean \pm standard deviation $(\mathrm{n}=3) .{ }^{*} \mathrm{P}<0.05,{ }^{* * *} \mathrm{P}<0.001$ vs. negative control. miR, microRNA.

DEL, together with $0.2 \mu \mathrm{g} \beta$-galactosidase control plasmid (Ambion) plus either 20 pmol miR-155 mimics or negative control of mimics were co-transfected into HCT-116 cells using Lipofectamine 2000 reagent. At 48 h after transfection, luciferase activity was measured using a Luciferase Assay System (Promega Corp.) according to the manufacturer's protocols.

Statistical analysis. All experiments were performed three times. Values are expressed as the mean \pm standard deviation. Student's t-test was performed for comparisons between two groups using Graphpad Prism 5.0 (Graphpad Software, Inc., San Diego, CA, USA). P $<0.05$ was considered to indicate a statistically significant difference.

\section{Results}

Upregulation of miR-155 promotes the proliferation, cell cycle and migration, while inhibiting apoptosis of colon cancer cells. After transfection with miR-155 mimics, the levels of miR-155 were detected by RT-qPCR. The results indicated that after transfection with miR-155 mimics, the miR-155 levels were increased to $48 \pm 3$.6-fold of those in cells transfected with negative control of mimics (Fig. 1A).

After transfection with miR-155 mimics, the viability of colon cancer cells was detected by an MTT assay. The results demonstrated that the cell viability was enhanced after transfection with miR-155 mimics (Fig. 1B). The colony formation capability of colon cancer cells was also measured after transfection. The results of the colony formation assay revealed that after transfection with miR-155 mimics, the number of colonies was $90 \pm 2.6$, which was significantly higher than that of cells transfected with negative control of mimics $(60.6 \pm 5.1$; $\mathrm{P}<0.001$; Fig. 1C). It was therefore demonstrated that miR-155 mimics promoted the proliferation of colon cancer cells.

As an important factor affecting the growth of cells, the cell cycle distribution was detected after transfection with miR-155 mimics or their corresponding negative control. Flow cytometric analysis revealed that the percentage of cells in G1 phase was decreased from 67.83 to $54.41 \%$ after transfection with miR-155 mimics, but the percentage of cells in $\mathrm{S}$ phase was increased from 23.78 to $36.16 \%$ (Fig. 1D). These results demonstrated that miR-155 mimics increased the percentage of cells in S phase. After transfection, an apoptosis assay was performed. Following transfection with negative control of miR-155 mimics, the early apoptotic rate was $13.83 \pm 0.76 \%$ and the late apoptotic rate was $2.51 \pm 0.31 \%$. However, after transfection with miR-155 mimics, the early apoptotic rate decreased to $3.72 \pm 0.59 \%$ and the late apoptotic rate decreased to $1.65 \pm 0.14 \%$ (Fig. 2A and B). These results demonstrated that miR-155 mimics inhibited apoptosis of colon cancer cells.

The migration capability of colon cancer cells after transfection was assessed using a wound healing assay. As presented in Fig. 2C and D, the migration rate of cells transfected with negative control of mimics was $0.148 \pm 0.015$, whereas that of cells transfected with miR-155 mimics was $0.265 \pm 0.18$ (Fig. 2C and D). These results demonstrated that miR-155 mimics promoted the migration of colon cancer cells.

Downregulation of miR-155 inhibits the proliferation, cell cycle and migration, while promoting apoptosis of colon 

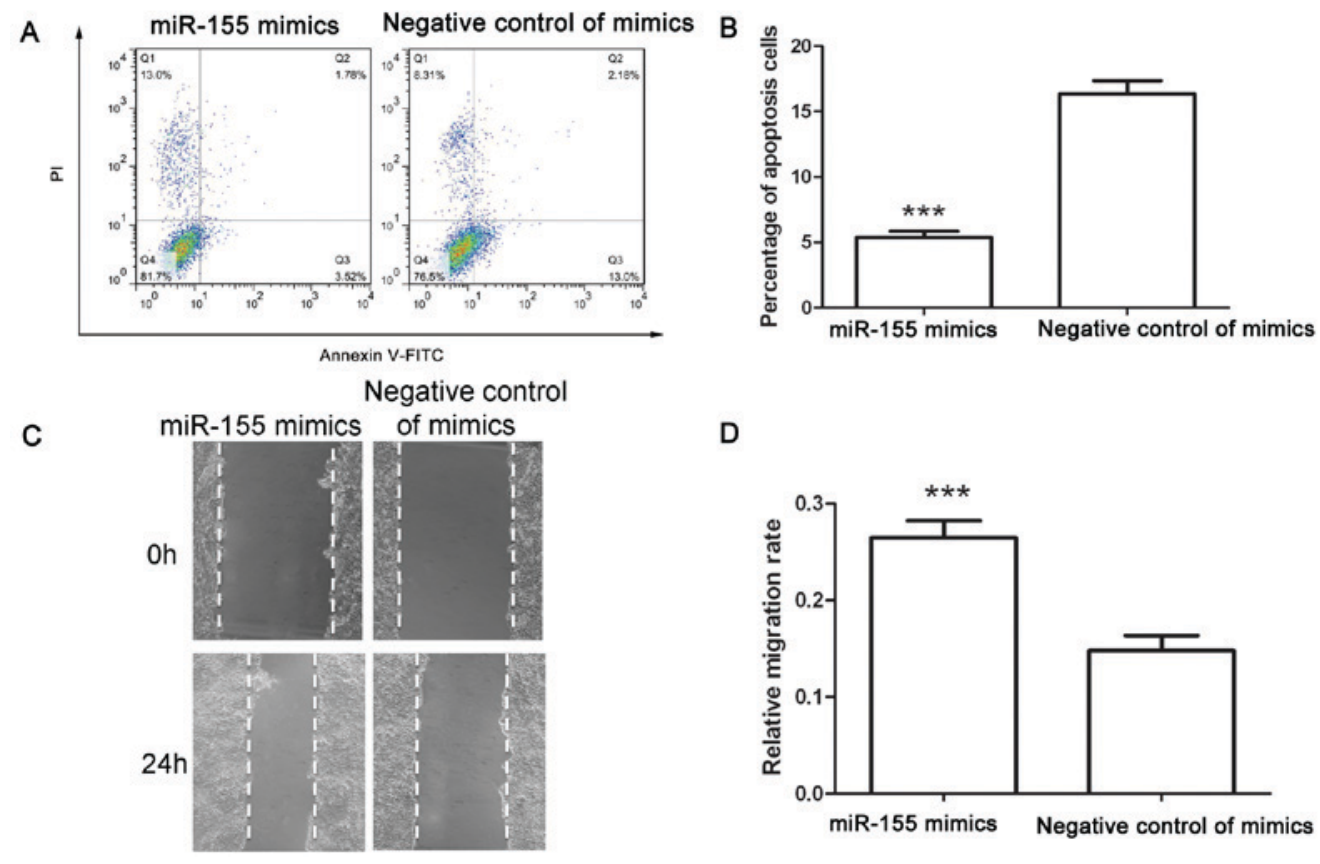

D

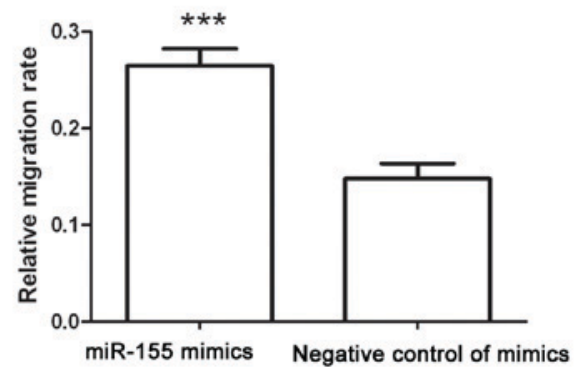

Figure 2. Upregulation of miR-155 promotes the migration and inhibits apoptosis of colon cancer cells. (A and B) Apoptosis was detected by flow cytometry after transfection with miR-155 mimics. (C and D) After transfection with miR-155 mimics, the migration of cells was detected by a wound healing assay. Magnification, $x 400$. Values are expressed as the mean \pm standard deviation $(n=3) .{ }^{* * *} \mathrm{P}<0.001$ vs. negative control. miR, microRNA; PI, propidium iodide; FITC, fluorescein isothiocyanate.
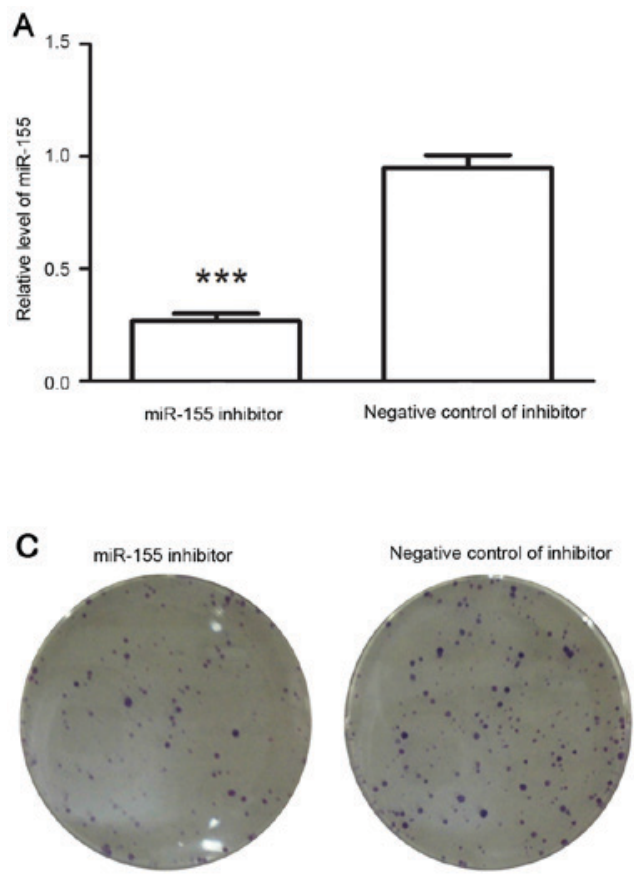

B
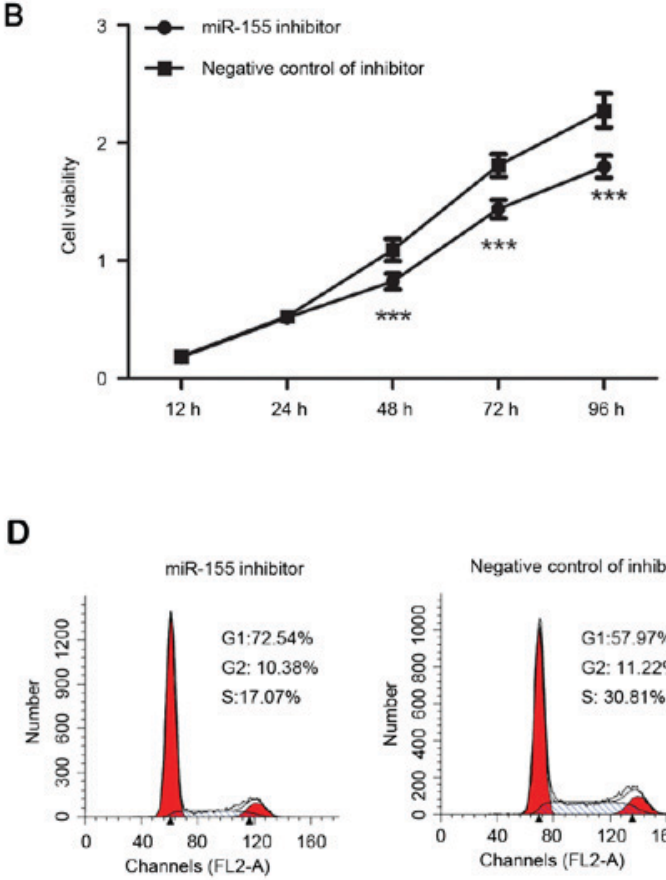

Figure 3. Downregulation of miR-155 inhibits the proliferation and cell cycle of colon cancer cells. (A) miR-155 levels were detected by reverse-transcription quantitative polymerase chain reaction after transfection with miR-155 inhibitor. The mRNA levels were normalized to U6 small hairpin RNA. (B) After transfection with miR-155 inhibitor, cell viability of colon cancer cells was detected by an MTT assay. (C) After transfection with miR-155 inhibitor, the colony formation capability was detected. (D) The cell cycle was analyzed by flow cytometry after transfection with miR-155 inhibitor. ${ }^{* * * *} \mathrm{P}<0.001$ vs. negative control of inhibitor. miR, microRNA.

cancer cells. After transfection with miR-155 inhibitor, the levels of miR-155 were detected by RT-qPCR. The results indicated that after transfection with miR-155 inhibitor, the relative miR-155 levels were decreased to $28 \pm 2 \%$ of those in negative control-transfected cells (Fig. 3A).
The cell viability and colony formation capability of colon cancer cells were then detected. The results demonstrated that, compared with that of cells transfected with negative control of inhibitor, the viability of colon cancer cells was inhibited after transfection with miR-155 inhibitor (Fig. 3B) and the number 
A

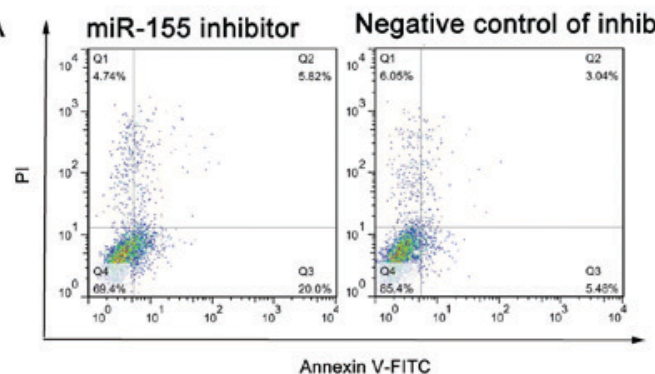

C

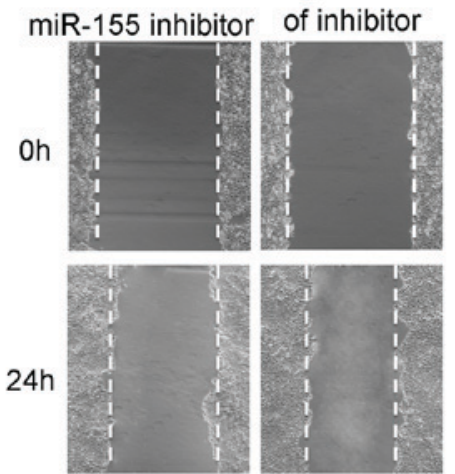

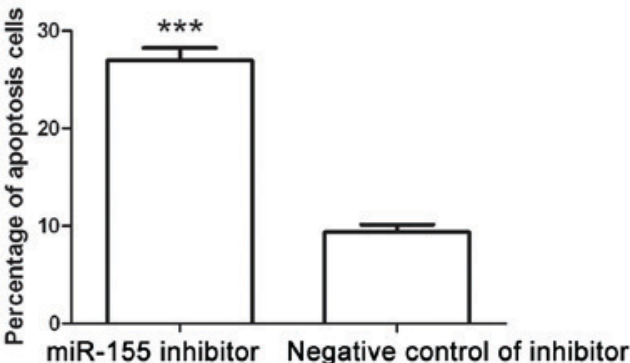

D

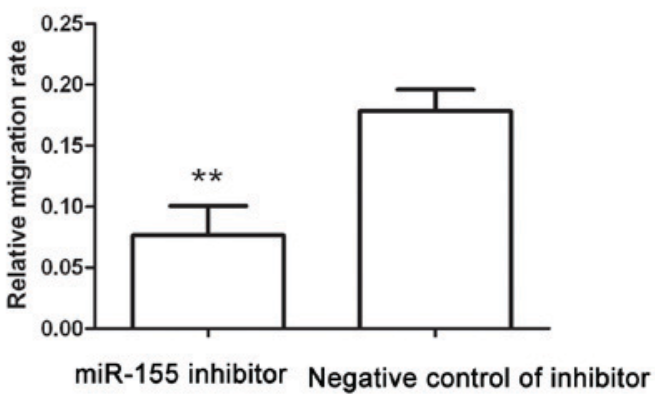

Figure 4. Downregulation of miR-155 inhibits the migration and promotes apoptosis of colon cancer cells. (A and B) Apoptosis was detected by flow cytometry. (C and D) The migration capability of cells was assessed by a wound healing assay after transfection with miR-155 inhibitor. Magnification, $\mathrm{x} 400$. Values are expressed as the mean \pm standard deviation $(\mathrm{n}=3) .{ }^{* * *} \mathrm{P}<0.01,{ }^{* * * *} \mathrm{P}<0.001$ vs. negative control of inhibitor. miR, microRNA; PI, propidium iodide; FITC, fluorescein isothiocyanate.

of colonies was decreased from $73.67 \pm 4.16$ to $48.33 \pm 3.05$ ( $\mathrm{P}<0.01$; Fig. 3C). It was therefore suggested that miR-155 inhibitor reduced the proliferation of colon cancer cells.

The cell cycle distribution was detected after transfection with miR-155 inhibitor or its corresponding negative control. The results demonstrated that the percentage of cells in G1 phase was increased from 57.97 to $72.54 \%$ after transfection with miR-155 inhibitor, but the percentage of cells in S phase was decreased from 30.81 to $17.07 \%$ (Fig. 3D). It was therefore indicated that miR-155 inhibitor increased the percentage of cells in G1 phase.

An apoptosis assay was performed after transfection with miR-155 inhibitor or its corresponding negative control. After transfection with negative control of miR-155 inhibitor, the early apoptotic rate was $6.49 \pm 0.90 \%$ and the late apoptotic rate was $2.88 \pm 0.15 \%$, whereas after transfection with miR-155 inhibitor, the early apoptotic rate was increased to $21.03 \pm 1.17 \%$ and the late apoptotic rate was increased to $5.92 \pm 0.29 \%$ (Fig. 4A and B). These results demonstrated that miR-155 inhibitor induced apoptosis of colon cancer cells.

The migration capability of colon cancer cells was detected after transfection with miR-155 inhibitor. As presented in Fig. $4 \mathrm{C}$ and $\mathrm{D}$, the migration rate of cells transfected with negative control of inhibitor was $0.178 \pm 0.018$, whereas that of cells transfected with miR-155 inhibitor was $0.076 \pm 0.025$. The wound healing assay demonstrated that miR-155 inhibitor reduced the migration of colon cancer cells.

$C B L$ is a direct target of $m i R-155$. CBL was predicted as a target of miR-155 by TargetScan. The levels of CBL were detected by RT-qPCR and western blot analysis. The RT-qPCR results demonstrated that the mRNA levels of CBL were decreased to $25.33 \pm 3.05 \%$ after transfection with miR-155 mimics, and increased to $3.51 \pm 0.27$-fold of those of the negative control group after transfection with miR-155 inhibitor (Fig. 5A). Western blot analysis provided similar results to those of RT-qPCR. The protein levels of CBL were decreased to $14 \pm 5.29 \%$ after transfection with miR-155 mimics and increased to $1.69 \pm 0.27$-fold of those of the negative control group after transfection with miR-155 inhibitor (Fig. 5B and C). These results demonstrated that $\mathrm{CBL}$ was regulated by miR-155.

To identify whether CBL is a direct target of miR-155, a luciferase reporter assay was performed. Plasmids containing WT, MUT or DEL were constructed as illustrated in Fig. 5D, and a luciferase reporter assay was then performed. As presented in Fig. 5D, co-transfection with WT plus miR-155 mimics resulted in a significant decreased in relative luciferase activity to $61 \pm 17 \%$ of that of the WT plus negative control of mimics group. However, there was no significant difference between the relative luciferase activities of cells transfected with MUT plus miR-155 mimics and MUT plus negative control of mimics. There was also no significant difference between the relative luciferase activities of cells transfected with DEL plus miR-155 mimics and DEL plus negative control of mimics. These results demonstrated that miR-155 bound to the 3'UTR of CBL and that CBL was a direct target of miR-155.

\section{Discussion}

In the present study, the effects of miR-155 on colon cancer cells were explored. Upregulation of miR-155 was found 


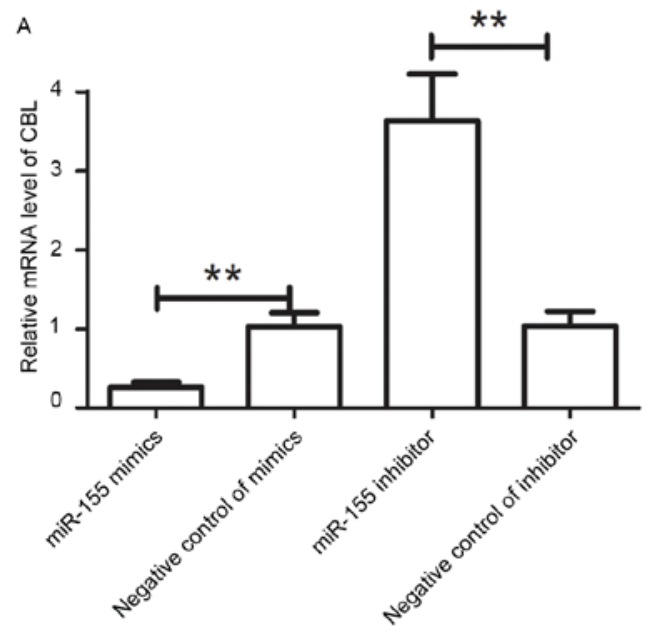

B

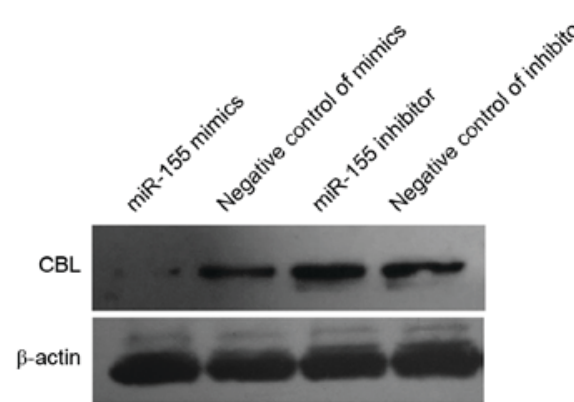

D
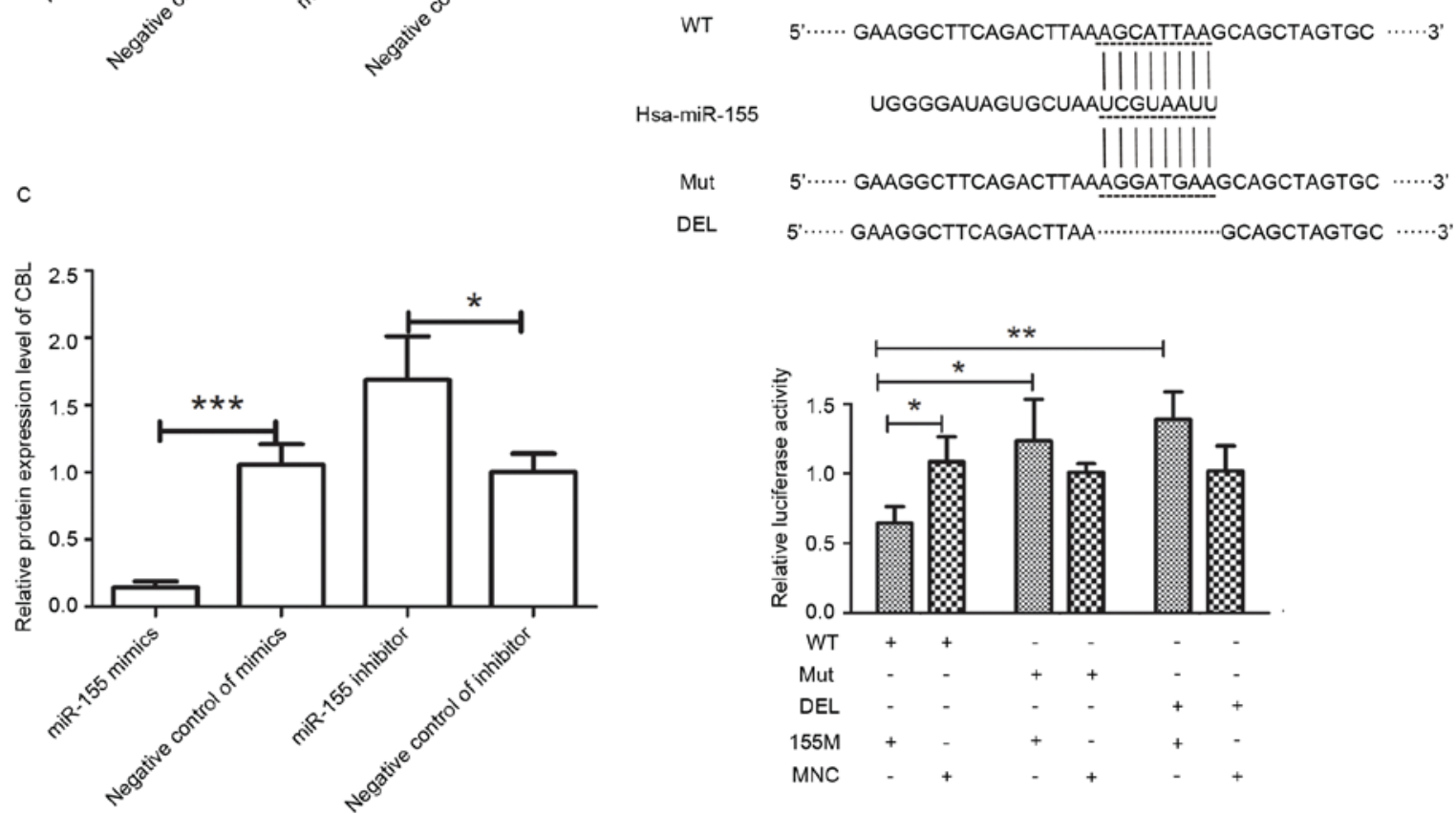

DEL

$5^{\prime} \cdots \cdots \cdot$ GAAGGCTTCAGACTTAA ……...........GCAGCTAGTGC …....

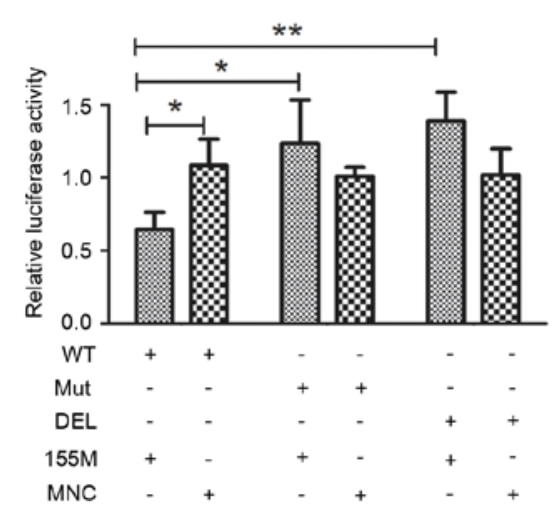

Figure 5. CBL is a direct target of miR-155. (A) After transfection with miR-155 mimics, miR-155 inhibitor or their corresponding negative control, the mRNA levels of CBL were detected by reverse-transcription quantitative polymerase chain reaction. (B and C) The protein levels of CBL were detected by western blot analysis after transfection with miR-155 mimics, miR-155 inhibitor or their corresponding negative control. (D) A luciferase reporter assay was performed to identify whether CBL is a direct target of miR-155. Values are expressed as the mean \pm standard deviation $(\mathrm{n}=3)$. ${ }^{*} \mathrm{P}<0.05,{ }^{* * *} \mathrm{P}<0.01,{ }^{* * * *} \mathrm{P}<0.001$ as indicated. miR, microRNA; CBL, casitas B-lineage lymphoma; hsa, Homo sapiens; DEL, deletion; WT, wild-type; Mut, mutated; 155M, miR-155 mimics; MNC, negative control miR.

to promote the proliferation and migration of colon cancer cells, while promoting cell cycle progression and inhibiting apoptosis. Conversely, downregulation of miR-155 was found to inhibit the proliferation and migration of colon cancer cells, cause cell cycle arrest and induce apoptosis. Further study demonstrated that CBL was a direct target of miR-155, through which miR-155 may exert its effects on the proliferation, migration, cell cycle and apoptosis.

Changes of miR expression frequently occur in cancer cells and are usually associated with tumorigenesis and the development of cancer. In numerous types of cancer, miR-155 promotes proliferation, migration and differentiation, and inhibits apoptosis $(11,19,22-27)$. However, in certain types of cancer, miR-155 represses proliferation and migration, and promotes apoptosis $(28,29)$. miR-155 therefore acts as either an oncomiR or tumor suppressor in different cancer cell types. In the present study, miR-155 was found to act as an oncomiR in colon cancer cells.
miR-155 has been reported to be overexpressed in colon cancer $(19,20)$; however, the roles of miR-155 in colon cancer have remained to be fully elucidated. In the present study, miR-155 was found to act as an oncomiR in colon cancer cells to promote the proliferation, cell cycle and migration, but inhibit apoptosis. Consistent with the results of the present study, Qu et al (19), Li et al (30) and Zhang et al (31) report that miR-155 is associated with the proliferation, migration and invasion of colon cancer cells. As an oncomiR, miR-155 may be a promising therapeutic target for colon cancer therapy. Nanoparticle-based anti-miR-155 therapy has been reported to have excellent therapeutic effects in an miR-155-dependent mouse model of lymphoma (32). miR-155 is frequently correlated with poor prognosis and may become a key target of colorectal carcinoma therapy.

In the present study, CBL was identified as a novel target of miR-155 using RT-qPCR, western blot analysis and a luciferase reporter assay. Moreover, Jablonska et al (33) also 
mentioned that CBL may be a target of miR-155. CBL is an E3 ubiquitin ligase, which has important roles in cell adhesion and migration (34). Migration is a multistep process involving extension of lamellipodia, formation of focal adhesions at the leading edge, translocation of the cell body, release of adhesive contacts and finally retraction at the cell rear (35). CBL is known to regulate the actin cytoskeleton, to ubiquitinate mDab1 and WAVE2 and to inhibit actin polymerization (34). CBL also binds to tubulin and microtubules through its tyrosine kinase-binding domain and regulates the microtubular network (36). CBL facilitates cytoskeletal rearrangements and matrix deposition via regulation of Ras-related C3 botulinum toxin substrate 1 (35), which is required for lamellipodia extension. CBL also regulates Ras homolog gene family, member A (35), which in turn regulates actomyosin contractility and is necessary for cells to move forward (37). In a different manner, CBL regulates migration by downregulation of growth factor receptors (38). Growth factors induce directional migration by promoting cell polarization, and CBL modulates the spatial distribution of growth factor receptors in cells through ubiquitinating the receptors. However, cells deficient of CBL were found to have severe migration defects, suggesting that CBL is required for cell migration (34).

$\mathrm{CBL}$ is also involved in the growth of cancer cells. Ectopic expression of CBL inhibited the proliferation of cancer cells and induced cell cycle arrest at G1 phase $(39,40)$. Knockdown of CBL was reported to impair colony formation capability (41) and induce apoptosis (42). Phosphatidylinositol 3 kinase (PI3K) has important roles in the regulation of proliferation and apoptosis, and CBL also interacts with PI3K and regulates proliferation and apoptosis (43). Increasing CBL expression resulted in decreased cell growth, increased cell apoptosis and inhibition of tumor development in a mouse model (44). In addition, $\mathrm{CBL}$ was reported to have a tumor suppressor role in colon cancer cells $(17,18)$, which was opposite to the effects of miR-155. This provided further evidence for the present hypothesis that CBL is a target of miR- 155 .

In the present study, miR-155 was indicated to promote the proliferation, arrest cell cycle at $\mathrm{S}$ phase, promote migration of colon cancer cells, and inhibit their apoptosis. CBL, whose biological functions are opposite to those of miR-155, was identified as a target of miR-155. The results of the present study demonstrated that miR-155 acted as an oncomiR in colon cancer cells through targeting CBL, and miR-155 may become a promising therapeutic target for colon cancer.

\section{Acknowledgements}

The authors would like to thank Dr Min Wang, Dr Hanrong Liu and Dr Song Han in The Branch of Shanghai First People's Hospital (Shanghai, China) for their guidance and help with the study design, experimental operation and data analysis as well as writing and revision of the manuscript.

\section{References}

1. Lagos-Quintana M, Rauhut R, Lendeckel W and Tuschl T: Identification of novel genes coding for small expressed RNAs. Science 294: 853-858, 2001.

2. Meltzer PS: Cancer genomics: Small RNAs with big impacts. Nature 435: 745-746, 2005.
3. Foshay KM and Gallicano GI: Small RNAs, big potential: The role of MicroRNAs in stem cell function. Curr Stem Cell Res Ther 2: 264-271, 2007.

4. Fabian MR, Sonenberg N and Filipowicz W: Regulation of mRNA translation and stability by microRNAs. Annu Rev Biochem 79: 351-379, 2010.

5. Calin GA and Croce CM: MicroRNA signatures in human cancers. Nat Rev Cancer 6: 857-866, 2006.

6. O'Connell RM, Kahn D, Gibson WS, Round JL, Scholz RL, Chaudhuri AA, Kahn ME, Rao DS and Baltimore D: MicroRNA-155 promotes autoimmune inflammation by enhancing inflammatory $\mathrm{T}$ cell development. Immunity 33: 607-619, 2010.

7. Calame K: MicroRNA-155 function in B Cells. Immunity 27: 825-827, 2007.

8. Vigorito E, Perks KL, Abreu-Goodger C, Bunting S, Xiang Z, Kohlhaas S, Das PP, Miska EA, Rodriguez A, Bradley A, et al: microRNA-155 regulates the generation of immunoglobulin class-switched plasma cells. Immunity 27: 847-859, 2007.

9. Yan L, Hu F, Yan X, Wei Y, Ma W, Wang Y, Lu S and Wang Z: Inhibition of microRNA-155 ameliorates experimental autoimmune myocarditis by modulating Th17/Treg immune response. J Mol Med (Berl) 94: 1063-1079, 2016.

10. Gao Y, Ma X, Yao Y, Li H, Fan Y, Zhang Y, Zhao C, Wang L, Ma M, Lei Z and Zhang X: miR-155 regulates the proliferation and invasion of clear cell renal cell carcinoma cells by targeting E2F2. Oncotarget 7: 20324-20337, 2016.

11. Zhang L, Wang W, Li X, He S, Yao J, Wang X, Zhang D and Sun X: MicroRNA-155 promotes tumor growth of human hepatocellular carcinoma by targeting ARID2. Int J Oncol 48: 2425-2434, 2016.

12. Sumara I, Maerki S and Peter M: E3 ubiquitin ligases and mitosis: Embracing the complexity. Trends Cell Biol 18: 84-94, 2008.

13. Zhang HG, Wang J, Yang X, Hsu HC and Mountz JD: Regulation of apoptosis proteins in cancer cells by ubiquitin. Oncogene 23: 2009-2015, 2004.

14. Bernassola F, Karin M, Ciechanover A and Melino G: The HECT family of E3 ubiquitin ligases: Multiple players in cancer development. Cancer Cell 14: 10-21, 2008.

15. Jing Z, Li L, Wang X, Wang M, Cai Y, Jin ZI and Zhang YE: High c-Cbl expression in gliomas is associated with tumor progression and poor prognosis. Oncol Lett 11: 2787-2791, 2016.

16. Severe N, Miraoui $\mathrm{H}$ and Marie PJ: The casitas B lineage lymphoma (Cbl) mutant G306E enhances osteogenic differentiation in human mesenchymal stromal cells in part by decreased Cbl-mediated platelet-derived growth factor receptor alpha and fibroblast growth factor receptor 2 ubiquitination. J Biol Chem 286: 24443-24450, 2011.

17. Shashar M, Siwak J, Tapan U, Lee SY, Meyer RD, Parrack P, Tan J, Khatami F, Francis J, Zhao Q, et al: c-Cbl mediates the degradation of tumorigenic nuclear $\beta$-catenin contributing to the heterogeneity in Wnt activity in colorectal tumors. Oncotarget 7: 71136-71150, 2016.

18. Wang L, Cao H, Lu N, Liu L, Wang B, Hu T, Israel DA, Peek RM Jr, Polk DB and Yan F: Berberine inhibits proliferation and down-regulates epidermal growth factor receptor through activation of Cbl in colon tumor cells. PLoS One 8: e56666, 2013.

19. Qu YL, Wang HF, Sun ZQ, Tang Y, Han XN, Yu XB and Liu K: Up-regulated miR-155-5p promotes cell proliferation, invasion and metastasis in colorectal carcinoma. Int J Clin Exp Pathol 8: 6988-6994, 2015.

20. Velazquez KT, Enos RT, McClellan JL, Cranford TL, Chatzistamou I, Singh UP, Nagarkatti M, Nagarkatti PS, Fan D and Murphy EA: MicroRNA-155 deletion promotes tumorigenesis in the azoxymethane-dextran sulfate sodium model of colon cancer. Am J Physiol Gastrointest Liver Physiol 310: G347-G358, 2016.

21. Livak KJ and Schmittgen TD: Analysis of relative gene expression data using real-time quantitative PCR and the 2(-Delta Delta C(T)) method. Methods 25: 402-408, 2001.

22. Mattiske S, Suetani RJ, Neilsen PM and Callen DF: The oncogenic role of miR-155 in breast cancer. Cancer Epidemiol Biomarkers Prev 21: 1236-1243, 2012.

23. Jiang S, Zhang HW, Lu MH, He XH, Li Y, Gu H, Liu MF and Wang ED: MicroRNA-155 functions as an OncomiR in breast cancer by targeting the suppressor of cytokine signaling 1 gene. Cancer Res 70: 3119-3127, 2010.

24. Sun Y, Wang M, Lin G, Sun S, Li X, Qi J and Li J: Serum microRNA-155 as a potential biomarker to track disease in breast cancer. PLoS One 7: e47003, 2012. 
25. Xie Q, Chen X, Lu F, Zhang T, Hao M, Wang Y, Zhao J, McCrae MA and Zhuang H: Aberrant expression of microRNA 155 may accelerate cell proliferation by targeting sex-determining region $\mathrm{Y}$ box 6 in hepatocellular carcinoma. Cancer 118 : 2431-2442, 2012.

26. Tiago DM, Conceição N, Caiado H, Laizé V and Cancela ML: Matrix Gla protein repression by miR-155 promotes oncogenic signals in breast cancer MCF-7 cells. FEBS Lett 590: 1234-1241, 2016.

27. Li S, Chen T, Zhong Z, Wang Y, Li Y and Zhao X: microRNA-155 silencing inhibits proliferation and migration and induces apoptosis by upregulating BACH1 in renal cancer cells. Mol Med Rep 5: 949-954, 2012.

28. Ma Z, Ma Y, Xia Q, Li Y, Li R, Chang W, Chen J, Leng Z and Tao K: MicroRNA-155 expression inversely correlates with pathologic stage of gastric cancer and it inhibits gastric cancer cell growth by targeting cyclin D1. J Cancer Res Clin Oncol 142: 1201-1212, 2016

29. Dai Y, Qiu Z, Diao Z, Shen L, Xue P, Sun H and Hu Y: MicroRNA-155 inhibits proliferation and migration of human extravillous trophoblast derived HTR-8/SVneo cells via down-regulating cyclin D1. Placenta 33: 824-829, 2012.

30. Li T, Yang J, Lv X, Liu K, Gao C, Xing Y and Xi T: miR-155 regulates the proliferation and cell cycle of colorectal carcinoma cells by targeting E2F2. Biotechnol Lett 36: 1743-1752, 2014.

31. Zhang GJ, Xiao HX, Tian HP, Liu ZL, Xia SS and Zhou T: Upregulation of microRNA-155 promotes the migration and invasion of colorectal cancer cells through the regulation of claudin-1 expression. Int J Mol Med 31: 1375-1380, 2013.

32. Babar IA, Cheng CJ, Booth CJ, Liang X, Weidhaas JB, Saltzman WM and Slack FJ: Nanoparticle-based therapy in an in vivo microRNA-155 (miR-155)-dependent mouse model of lymphoma. Proc Natl Acad Sci USA 109: E1695-E1704, 2012.

33. Jablonska E, Gorniak P, Prusisz W, Kiliszek P, Szydlowski M, Sewastianik T, Bialopiotrowicz E, Polak A, Prochorec-Sobieszek M, Szumera-Cieckiewicz A, et al: Downregulation of deptor By miR-155 promotes cell survival through activation of $\mathrm{PI} 3 \mathrm{~K} / \mathrm{AKT}$ and $\mathrm{NFkB}$ signaling in ABC-type diffuse large B-cell Lymphomas. Blood 128: 1761, 2016.
34. Huang C: Roles of E3 ubiquitin ligases in cell adhesion and migration. Cell Adh Migr 4: 10-18, 2010.

35. Teckchandani AM, Panetti TS and Tsygankov AY: c-Cbl regulates migration of v-Abl-transformed NIH 3 T3 fibroblasts via Rac1. Exp Cell Res 307: 247-258, 2005.

36. Teckchandani AM, Birukova AA, Tar K, Verin AD and Tsygankov AY: The multidomain protooncogenic protein $\mathrm{c}-\mathrm{Cbl}$ binds to tubulin and stabilizes microtubules. Exp Cell Res 306: $114-127,2005$.

37. Mitchison TJ and Cramer LP: Actin-based cell motility and cell locomotion. Cell 84: 371-379, 1996.

38. Jekely G, Sung HH, Luque CM and Rørth P: Regulators of endocytosis maintain localized receptor tyrosine kinase signaling in guided migration. Dev Cell 9: 197-207, 2005.

39. Shen $M$ and Yen A: c-Cbl tyrosine kinase-binding domain mutant G306E abolishes the interaction of c-Cbl with CD38 and fails to promote retinoic acid-induced cell differentiation and G0 arrest. J Biol Chem 284: 25664-25677, 2009.

40. Lo FY, Tan YH, Cheng HC, Salgia R and Wang YC: An E3 ubiquitin ligase: $\mathrm{c}-\mathrm{Cbl}$ : A new therapeutic target of lung cancer. Cancer 117: 5344-5350, 2011.

41. An W, Nadeau SA, Mohapatra BC, Feng D, Zutshi N, Storck MD, Arya P, Talmadge JE, Meza JL, Band V and Band H: Loss of $\mathrm{Cbl}$ and Cbl-b ubiquitin ligases abrogates hematopoietic stem cell quiescence and sensitizes leukemic disease to chemotherapy. Oncotarget 6: 10498-10509, 2015.

42. Kim SY, Kim JH and Song JJ: c-Cbl shRNA-expressing adenovirus sensitizes TRAIL-induced apoptosis in prostate cancer DU-145 through increases of DR4/5. Cancer Gene Ther 20: 82-87, 2013.

43. Brennan T, Adapala NS, Barbe MF, Yingling V and Sanjay A: Abrogation of Cbl-PI3K interaction increases bone formation and osteoblast proliferation. Calcif Tissue Int 89: 396-410, 2011.

44. Severe N, Dieudonné FX, Marty C, Modrowski D, Patiño-García A, Lecanda F, Fromigué O and Marie PJ: Targeting the E3 ubiquitin casitas B-lineage lymphoma decreases osteosarcoma cell growth and survival and reduces tumorigenesis. J Bone Miner Res 27: 2108-2117, 2012. 